\title{
Rejoinder to Hadley
}

Marcia Lynn Whicker, Rutgers University, Newark

Malcolm Jewell, University of Kentucky

Charles D. Hadley has made several interesting points, including some legitimate criticisms of our study. Some criticisms, however, are less relevant and do not undermine the integrity of our effort. We shall discuss his points in sequence:

Confusion over "critical" and "realigning" elections. Hadley contends that we have confused critical and realigning elections. We acknowledge that perhaps we have been too loose with our use of terminology. His point that critical elections, representing a fundamental shift in the political attitudes and preferences of the populace, may be divided into realigning and converting subsets is well taken. We have erred in using the terms "critical election" and "realigning election" interchangeably, and should have restricted ourselves to using the former. This misuse of terms, however, is incidental to our analysis, since we have analyzed all critical elections from the founding of the country to the present, with special attention to the four critical elections about which there is the greatest agreement $(1828,1860$, 1896, and 1932).

The impact of expansion of Congressional membership. Hadley's second point is that because the number of members of Congress expanded during part of our study period, our longitudinal analyses are invalid. Because of this expansion, he contends, there always is a substantial number of newcomers. He recommends that we, like Seligman and King, study the backgrounds of defeated and newly elected members of Congress. Several points can be made in response to this criticism:

1. Institutions are dynamic organisms, not constants. All institutions expand, grow, decline, and/or shrink across a long period of time. Extending Hadley's logic, we should not examine any institution that changes in size (the number of members) across time. In an ideal world, or in a carefully designed and controlled experiment, size would be held constant. In fact, one of the authors has pioneered in the use of computer simulation models precisely to hold constant factors such as institutional size, by setting them as parameters. These models of institutional change mostly have been ignored or rejected by political scientists, especially institutional scholars,

The American Review of Politics, Vol. 14, Spring, 1993: 123-127

(C)1993 The American Review of Politics 
who contend that because such models hold factors that have changed in the real world as constants in order to approximate an experimental design, they are unrealistic.

To forego longitudinal analyses of the total membership of institutions because of changes of size seems excessive. Indeed, to correct or fill in the gaps in the limited and interrupted longitudinal work of Brady and others was precisely why we conducted this analysis in the first place. Legislative and congressional scholars have been "blessed" with constant size (if considering only membership, not support staff and bureaus), yet this situation is relatively unique in the study of institutions. In public administration, the presidency, and even to a lesser extent the courts, scholars have confronted institutional growth across time, and have conducted longitudinal studies despite these impediments.

2. Hadley is concerned that the increase in membership means that until 1911, when congressional membership was fixed at 435 , there always will be a number of newcomers. While he does not extend his argument to its logical conclusion, this implies that a bias would exist prior to 1911 in favor of the newcomer explanation of critical elections, as expressed by growing percentages of newcomers during that period.

Two responses to this come to mind. First, we found little support for the newcomer explanation of critical elections. If biases from the expansion of newcomers as a product of growth in size did contaminate our analysis, as Hadley suggests, our findings would have been suspect if we had found support for the newcomer explanation. Yet, we found the reverse. Indeed, prior to 1911, as our Table 2 shows, the percentage of newcomers remained constant or declined from the preceding period, with the exception of the increase in the percentage of newcomers to 49.6 percent during one period (1842-1859). Yet, Hadley notes that size of Congress actually decreased by 10 in 1840, the one time during the pre-1911 period when membership decreased. Plainly, the bias that Hadley implies would favor the newcomer explanation is not borne out in our data or in our conclusions.

Second, the growth in institutional size is less of a problem than Hadley suggests when analyzing percentages of newcomers. Suppose, for argument, that Congress were sized at 100, with 20 percent turnover in old membership from the last Congress, plus newcomers resulting from the growth in institutional size. Suppose Congress grew at a rate of 20 percent with each census. The bias Hadley fears (that the growth, rather than any shift in popular preferences, will cause the percentage of newcomers to increase) occurs only in the first period of growth. Thus, in the first period with no growth, 20 percent of the 100 member Congress consists of newcomers. In the second period, Congress grows 20 percent, to a membership of 120 . 
What percentage are newcomers? Twenty percent of the old membership $(.2 \times 100)$ plus the 20 added seats means 33 percent (40 out of 120$)$ are newcomers. This, indeed, represents rapid growth, independent of popular preferences or generational shifts.

Consider, however, the third period. Twenty percent of the old membership (120) are newcomers $(.2 \times 120=24)$ plus the 20 percent growth in institutional size that necessarily are newcomers (another 24 ) results in a total of 48 newcomers in a Congress of 144 (again, 33 percent newcomers). If the institutional growth is relatively constant, then the confounding effect of institutional expansion occurs only in the first period of such expansion.

Let us continue our analysis for one more period to verify this point. Consider period four. The number of newcomers is 20 percent of the old membership (.2 X $144=28.8$ or 29 newcomers), plus the 20 percent growth in size (another 29 newcomers), for a total of 58 newcomers out of a new membership of 173 , or 33 percent. The principle holds. Thus, the institutional growth that Hadley warns against introduces bias in the percentage of newcomers only in the first period of growth. Admittedly, as Hadley's figures show, the real growth in seats is not as steady as in the above example, but the principle illustrated here shows that the bias is not so great as Professor Hadley fears.

3. Hadley suggests that, like Seligman and King, we should study defeated and newly-elected members of Congress only. We respond, first, that Seligman and King already have done it, so redoing it plows old ground; and second, that our purpose was to study sources of institutional change in Congress that correlated with major periods of electoral change and policy shift. We could not have extrapolated about institutional change from looking only at a subset of members, i.e., those cases in which turnover took place. An examination of institutional change necessitates analyzing the total institutional membership, since seats that did not turn over as well as those that did had a vote and an impact on congressional outputs. Further, if we had looked only at occupants of seats that turned over, with whom would we have compared them? Our concern was that newcomers were different from oldtimers who remained in the institution, not that newcomers were different from those just defeated or retired.

The concern over policy shifts as reflected by legislation. Hadley takes issue with our assumption that critical elections were followed by shifts in major policy, as reflected by congressional legislation. He suggests as a model the work of Gates, who studied state statutes rejected by the U.S. Supreme Court as unconstitutional. We would raise two points in response.

First, Supreme Court decisions in critical election periods are likely only to be linked tangentially to institutional changes in Congress, given the 
long tenure that Justices serve, the uneven rate of appointment, and the passive nature of the courts in soliciting cases on which to make major policy shifts. Our focus was on the institutional changes in Congress, not in the court.

Second, we acknowledge that Hadley has a good research idea: do critical election periods correlate with major shifts, changes, and/or qualitative differences in congressional output, as reflected in statutes passed? This idea, however, is a separate (and likely very comprehensive) study, and was not our focus. To fault us for not studying what he thinks is more interesting (and we agree the topic is interesting) does not undermine the credibility of our current analysis.

The use of periods versus single years. Hadley contends our analysis is weakened by our aggregation of data into five and fifteen year periods to study generational change. However, we counter that, first, the use of periods smooths out some of the factors about which Hadley earlier expressed concern (such as institutional growth). Second, we use the periods as modes, to identify the modal age group in any period of stability and decay. We contend that age is as good an indicator of the socializing experiences of a cohort as is available, or even possible. Third, we supplement our analyses by using means (of age), and thus do not rely strictly on modal categories of 5 and 15 years. Fourth, for each critical and midyear election, we analyze single year shifts in our three explanatory factors, as well as the shifts across the entire election period. People who read the article and get a headache following the large number of statistics reported discretely for each critical election and midyear election as well as for each stability and decay period may differ with Professor Hadley's assessment that we have analyzed too little.

The importance of finding that political party outweighs turnover and cohort effects. Finally, Hadley contends that our finding that party outweighs the other two explanations is to be expected, and even trivial. In one sense, he is right: we analyzed major election periods already defined in the literature as critical because of some form of party shift, and found that the best explanation of policy shifts was party shifts in institutional membership. Equally important and not as obvious, however, are our subsidiary conclusions: that turnover and cohort effects are not good explanations. That contribution is not trivial. Further, we have set the stage for further analyses analyzing what is important about parties. In an era in which party has been pronounced to be in decline, showing that it has been a driving force throughout our history may not be trivial after all.

In conclusion, Professor Hadley has pointed to our inappropriate interchange of the terms critical and realigning elections, and has suggested an 
important and major future undertaking for readers of this exchange. Further, he has caused us to justify more fully our analysis. We pronounce these contributions non-trivial. 
